\title{
Vascular Endothelial Growth Factor Causes Pulmonary Vasodilation through Activation of the Phosphatidylinositol-3-Kinase-Nitric Oxide Pathway in the Late-Gestation Ovine Fetus
}

\author{
THERESA R. GROVER, JEANNE P. ZENGE, THOMAS A. PARKER, AND STEVEN H. ABMAN \\ Pediatric Heart Lung Center and Department of Pediatrics [T.R.G., J.P.Z., T.A.P., S.H.A.], University of \\ Colorado School of Medicine, Denver, Colorado 80045, U.S.A.
}

\begin{tabular}{|c|c|}
\hline \multicolumn{2}{|c|}{ ABSTRACT } \\
\hline $\begin{array}{l}\text { Vascular endothelial growth factor (VEGF) causes vasodila- } \\
\text { tion in adult models of peripheral vascular disease and myocar- } \\
\text { dial ischemia through the acute release of nitric oxide (NO). } \\
\text { However, the hemodynamic effects of VEGF and its effects on } \\
\text { NO production have not been studied in the developing lung } \\
\text { circulation. We hypothesized that VEGF causes fetal pulmonary } \\
\text { vasodilation, and that its actions are mediated through the release } \\
\text { of endogenous NO. We performed surgery in } 16 \text { fetal lambs } \\
\text { (125-135 d gestation; term = } 147 \mathrm{~d} \text { ), and placed catheters in the } \\
\text { main pulmonary artery, aorta, and left atrium to measure pres- } \\
\text { sures. An ultrasonic flow transducer was placed on the left } \\
\text { pulmonary artery (LPA) to measure blood flow, and a catheter } \\
\text { was placed in the LPA for local drug infusion. Pulmonary } \\
\text { vascular resistance in the left lung was calculated as pulmonary } \\
\text { artery pressure minus left atrial pressure divided by LPA flow. } \\
\text { Fetal lambs were treated with brief infusions of recombinant } \\
\text { human VEGF (dose, } 0.5-2.0 \mu \text { g) into the LPA. Recombinant } \\
\text { human VEGF infusions acutely increased LPA flow by up to } \\
3 \text {-fold ( } p<0.02) \text { and decreased pulmonary vascular resistance } \\
\text { by } 65 \% \text { ( } p<0.05 \text { ) in a dose-related fashion, without affecting } \\
\text { aortic pressure or heart rate. To determine the mechanism of } \\
\text { VEGF-induced vasodilation, we studied the effects of nitro-L- } \\
\text { arginine, an NO synthase inhibitor, and LY294002, a phospha- } \\
\text { tidylinositol-3-kinase inhibitor, on the response to VEGF. We } \\
\text { found that pretreatment with either nitro-L-arginine or LY294002 }\end{array}$ & $\begin{array}{l}\text { completely inhibited the vasodilator response to recombinant } \\
\text { human VEGF ( } p<0.005) \text {. These findings suggest that recom- } \\
\text { binant human VEGF causes fetal pulmonary vasodilation, and } \\
\text { that this response is likely mediated by the release of NO through } \\
\text { activation of phosphatidylinositol-3-kinase. (Pediatr Res 52: } \\
\text { 907-912, 2002) } \\
\text { Abbreviations } \\
\text { VEGF, vascular endothelial growth factor } \\
\text { NO, nitric oxide } \\
\text { NOS, NO synthase } \\
\text { MPA, main pulmonary artery } \\
\text { Ao, aorta } \\
\text { LA, left atrium } \\
\text { LPA, left pulmonary artery } \\
\text { PVR, pulmonary vascular resistance } \\
\text { MPAP, MPA pressure } \\
\text { AoP, Ao pressure } \\
\text { LAP, LA pressure } \\
\text { L-NA, nitro-L-arginine } \\
\text { PI-3-K, phosphatidylinositol-3-kinase } \\
\text { eNOS, endothelial NOS } \\
\text { Qp, pulmonary blood flow } \\
\text { BL, baseline } \\
\text { HR, heart rate }\end{array}$ \\
\hline
\end{tabular}

VEGF is a potent endothelial cell mitogen with angiogenic and vascular permeability properties (1-3). VEGF is critical to early vascular development inasmuch as gene ablation of a single allele of VEGF in the mouse prevents normal vascular development and causes early embryonic lethality $(4,5)$.

Received February 12, 2002; accepted June 25, 2002

Correspondence: Theresa R. Grover, M.D., University of Colorado Health Sciences Center, Department of Pediatrics, Section of Neonatology, 13243 E. 23rd Avenue, Building 260, F441, Aurora, CO 80045, U.S.A.; e-mail: grover.theresa@tchden.org

Supported in part by grants from the March of Dimes and the NIH (HL46481, HL68702).

DOI: 10.1203/01.PDR.0000036363.88804.20
VEGF signaling not only stimulates vascular growth, but also modulates endothelial cell survival and function $(6,7)$. In particular, VEGF treatment up-regulates eNOS in endothelial cells in vitro (8) and improves systemic blood flow in vivo (9). Although VEGF is clearly essential for early lung vascular structure and growth, the effects of VEGF on pulmonary vascular tone and reactivity during late fetal life are unclear.

Exogenous VEGF administration causes vasodilation in both local and systemic adult vascular beds (10-12). Several novel and exciting therapeutic interventions have recently examined the role of VEGF in manipulation of angiogenesis and maintenance of endothelial function in adult models of vascu- 
lar disease, including its use in ischemic limb $(13,14)$ and myocardial disease $(15,16)$. These studies have demonstrated improved collateral blood vessel development and endothelium-dependent blood flow after local administration of VEGF. Hemodynamic studies in adult models have also shown that VEGF is a potent vasodilator (10-12), causing a rapid fall in vascular resistance and increased blood flow. Whether VEGF also causes vasodilation in the developing pulmonary circulation is unknown.

VEGF-induced vasodilation is mediated at least in part through acute release of NO. VEGF stimulates eNOS and inducible NOS mRNA and protein expression under a variety of conditions $(8,17)$. In vivo studies have shown that VEGF dramatically decreases systemic blood pressure and resistance and improves blood flow, and these changes are inhibited by pretreatment with NOS antagonists $(10,12,18)$. Furthermore, VEGF stimulates NO release through phosphorylation of Akt (protein kinase B) by PI-3-K activation in both in vitro and in vivo models of adult systemic vascular disease (19-22). Whether VEGF causes NO-mediated vasodilation through this signal transduction pathway in the developing pulmonary circulation has not been studied.

Therefore, we hypothesized that VEGF is a vasodilator of the fetal pulmonary circulation, and that its actions are mediated through the release of endogenous NO. To address this question, we examined the pulmonary hemodynamic response to VEGF infusions and determined its mechanism of action in the fetal lung.

\section{METHODS}

\section{Surgical Preparation}

All procedures were reviewed and approved by the Animal Care and Use Committee at the University of Colorado Health Sciences Center (Denver, CO, U.S.A.). Sixteen mixed-breed (Columbia-Rambouillet) pregnant ewes between 125 and $135 \mathrm{~d}$ gestation were fasted for $48 \mathrm{~h}$ before surgery. Ewes were sedated with intramuscular Buprenex $(0.6 \mathrm{mg})$ and i.v. ketamine $(60 \mathrm{mg})$ and diazepam $(10 \mathrm{mg})$, and intratracheally intubated. Ewes were anesthetized using inhaled isoflurane ( $2 \%$ to $3 \%$ ), and remained sedated but breathed spontaneously throughout surgery. Under sterile conditions, the left forelimb of the fetal lamb was delivered through a uterine incision. A skin incision was made under the left forelimb after local infiltration with $1 \%$ lidocaine. Polyvinyl catheters were inserted into the axillary artery and advanced into the ascending Ao. A left axillary to sternal thoracotomy exposed the heart and great arteries. Polyvinyl catheters were inserted into the LPA, MPA, and LA by direct puncture and secured into position with purse-string sutures. A 6-mm ultrasonic flow transducer (Transonic Systems, Ithaca, NY, U.S.A.) was placed around the LPA to measure blood flow to the left lung (Qp). A catheter was placed in the amniotic cavity to serve as a pressure referent. The thoracotomy incision was closed in layers. The uteroplacental circulation was kept intact, and the fetus was gently replaced in the uterus. Ampicillin (500 mg) was added to the amniotic cavity before closure of the hyste- rotomy. The ewe was allowed to recover from surgery for $48 \mathrm{~h}$ before fetal drug administration and hemodynamic studies.

\section{Physiologic Measurements}

The Ao, MPA, and LA catheters were connected to a computer-monitored pressure transducer and recorder (Biopac Systems, Santa Barbara, CA, U.S.A.). Pressures were referenced to amniotic pressures, and the pressure transducer was calibrated with a mercury manometer. The flow transducer cable was attached to an internally calibrated flowmeter (Transonic Systems) for continuous measurements of LPA flow. The absolute values of flow were determined from phasic blood flow signals as previously described (23). PVR in the left lung was calculated with the following equation: PVR (mm $\left.\mathrm{Hg} \cdot \mathrm{mL}^{-1} \cdot \mathrm{min}\right)=($ mean MPAP - mean LAP $) / \mathrm{Q}_{\mathrm{LPA}}$. Arterial blood gas tensions, $\mathrm{pH}, \mathrm{Hb}$, oxygen saturation, and methemoglobin were measured from blood samples that were drawn from the Ao catheter and measured at $39.5^{\circ} \mathrm{C}$ with a blood gas analyzer and hemoximeter (model OSM-3, Radiometer, Copenhagen, Denmark).

\section{Study Drugs}

rhVEGF (R\&D Systems, Inc., Minneapolis, MN, U.S.A.) was dissolved in PBS (1 mg/mL stock solution) and stored at $4^{\circ} \mathrm{C}$. The required amount of solution was drawn up in a sterile syringe at room temperature at the time of study. The drug was infused into the LPA catheter for $1 \mathrm{~min}$, and followed by infusion of $1 \mathrm{~mL}$ of saline.

L-NA (10 mg, Sigma Chemical Co., St. Louis, MO, U.S.A.) was dissolved in $2 \mathrm{~mL}$ of normal saline plus $2-3$ drops $\mathrm{HCl}$, and titrated with $\mathrm{NaOH}$ to achieve a $\mathrm{pH}$ of 7.4. The drug was infused into the LPA by an infusion pump set to deliver $10 \mathrm{mg}$ for a 10-min period. L-NA was prepared immediately before drug administration, and the dose chosen was based on previous studies from our laboratory (24).

LY294002 (2-(4-morpholinyl)-8-phenyl-4H-1-benzopyran4-one), a specific PI-3-K inhibitor (21) (Calbiochem, San Diego, CA, U.S.A.) was dissolved in DMSO $(5 \mathrm{mg} / \mathrm{mL}$ stock solution), then diluted with normal saline for a final concentration of $0.5 \mathrm{mg} / \mathrm{mL}$. The drug was infused into the LPA catheter for $1 \mathrm{~min}$, and followed by $1 \mathrm{~mL}$ of saline infusion.

\section{Experimental Design}

Protocol 1: Hemodynamic effects of acute rhVEGF administration. The purpose of this protocol was to determine the effects of acute intrapulmonary administration of rhVEGF on fetal pulmonary hemodynamics. After a 48 -h recovery period after surgery, BL hemodynamic measurements were recorded for $\mathrm{Q}_{\mathrm{LPA}}$, MPAP, AoP, LAP, and HR $(n=6)$. After BL measurements were stable for a 30 -min period, $\operatorname{rhVEGF}(1 \mu \mathrm{g})$ was infused into the LPA for $1 \mathrm{~min}$. Hemodynamic measurements were recorded every $10 \mathrm{~min}$ for an additional $30 \mathrm{~min}$ after drug administration. Arterial blood gas tensions were obtained before and approximately 5 min after drug administration. 
A dose-response study was performed to determine the dosage needed for optimal response. After a stable BL period, rhVEGF was infused at one of several doses $(0.5,1$, and $2 \mu \mathrm{g}$; $n=6$ ). Each dose was administered no more frequently than every $24 \mathrm{~h}$ because of concerns for tachyphylaxis. Each dose was infused for $1 \mathrm{~min}$, and hemodynamic measurements recorded every $10 \mathrm{~min}$ for $30 \mathrm{~min}$ after drug administration. Dosage of drug administration was randomly assigned.

To determine whether lambs develop tachyphylaxis after repeat rhVEGF infusions, lambs were treated with serial doses of rhVEGF ( $1 \mu \mathrm{g} ; n=4)$. After BL measurements were obtained, lambs were treated with rhVEGF $(1 \mu \mathrm{g})$, and hemodynamics were measured every $10 \mathrm{~min}$ for $30 \mathrm{~min}$. A second and third dose (each $1 \mu \mathrm{g}$ ) were administered 30 min apart in the same manner after allowing pulmonary blood flow to return to $\mathrm{BL}$ values.

Protocol 2: Effects of NO inhibition on VEGF-induced pulmonary vasodilation. The purpose of this protocol was to determine whether VEGF-induced pulmonary vasodilation was mediated through $\mathrm{NO}$ production. After a stable BL period, rhVEGF $(1 \mu \mathrm{g})$ was infused into the LPA $(n=7)$. Hemodynamic measurements were recorded every $10 \mathrm{~min}$ for $40 \mathrm{~min}$. The following day, fetal lambs were treated with LNA $(10 \mathrm{mg})$, infused for $10 \mathrm{~min}$ into the LPA catheter, followed by rhVEGF $(1 \mu \mathrm{g})$. Hemodynamic measurements were recorded every $10 \mathrm{~min}$ for an additional $40 \mathrm{~min}$.

Protocol 3: Effects of PI-3-K inhibition on VEGF-induced pulmonary vasodilation. The purpose of this protocol was to determine whether VEGF causes pulmonary vasodilation by activating PI-3-K. After BL measurements were recorded for 30 min, fetal lambs $(n=4)$ were treated with VEGF $(1 \mu \mathrm{g})$ in the LPA, and hemodynamic measurements were recorded for 40 min. The following day, a specific PI-3-K inhibitor, LY294002 (2 mg) (21) was infused in the LPA, followed by rhVEGF $(1 \mu \mathrm{g})$. Hemodynamic measurements were recorded every $10 \mathrm{~min}$ for an additional $40 \mathrm{~min}$. Arterial blood gas tensions were obtained before and after drug administration. The dosage for LY294002 was based on previous in vivo studies $(20,21,25)$.

\section{Statistical Analysis}

Statistical analysis of hemodynamic data was performed using one-way ANOVA. When significant differences were identified, post hoc analysis was performed with StudentNewman-Keuls test. All statistical measurements were performed using a commercially available statistics package (GraphPad Prism, GraphPad Software, Inc., San Diego, CA, U.S.A.). The level of significance was set at $p<0.05$. The results are reported as mean \pm SEM.

\section{RESULTS}

\section{Protocol 1: Hemodynamic Effects of Acute rhVEGF Administration}

Intrapulmonary administration of rhVEGF $(1 \mu \mathrm{g})$ caused a nearly 3 -fold rise in rise pulmonary blood flow (Qp; $186 \pm 39$ $\mathrm{mL} / \mathrm{min}$ after treatment versus $67 \pm 13 \mathrm{~mL} / \mathrm{min}$ at $\mathrm{BL} ; p<$
0.02 ; Fig. $1 A)$ and a $65 \%$ fall in PVR $(0.30 \pm 0.1 \mathrm{~mm}$ $\mathrm{Hg} \cdot \mathrm{mL}^{-1} \cdot \min$ versus $0.84 \pm 0.2 \mathrm{~mm} \mathrm{Hg} \cdot \mathrm{mL}^{-1} \cdot \min ; p<0.05$; Fig. $1 B$ ). This response was maximal $3-5 \mathrm{~min}$ after infusion was completed, and was sustained for $10 \mathrm{~min}$. There was no effect of rhVEGF on MPAP, AoP, HR, or arterial blood gas tensions (Table 1).

Dose-response study. The dose-response study demonstrated a consistent rise in Qp and fall in PVR at each of the three treatment doses $(0.5,1$, and $2 \mu \mathrm{g})$ when compared with BL values. In this study, the higher doses (1 and $2 \mu \mathrm{g})$ increased Qp and reduced PVR more than the lowest dose of rhVEGF (0.5 $\mu \mathrm{g}$; Fig. 2). There was no difference in vasodilator response between the 1- $\mu \mathrm{g}$ and $2-\mu \mathrm{g}$ doses.

Tachyphylaxis. Repeated administration of rhVEGF $(1 \mu \mathrm{g})$ attenuated pulmonary vasodilation (Fig. 3). The initial dose of rhVEGF increased pulmonary blood flow by $184 \pm 25 \%$, whereas the subsequent doses (doses 2 and 3) given $30 \mathrm{~min}$ apart resulted in a smaller rise in Qp (75 $\pm 4 \%$ increase in Qp for dose 2 , and $64 \pm 28 \%$ increase for dose $3 ; p<0.05$ versus dose 1 for both).

\section{Protocol 2: Effects of NO Inhibition on VEGF-Induced Pulmonary Vasodilation}

Pretreatment of fetal lambs with the NO antagonist, L-NA, completely blocked VEGF-induced vasodilation. VEGF caused pulmonary blood flow to increase $140 \%$, from $54 \pm 11$ $\mathrm{mL} / \mathrm{min}$ at $\mathrm{BL}$ to $130 \pm 20 \mathrm{~mL} / \mathrm{min}$ (VEGF versus $\mathrm{BL} ; p<$ 0.05 ; Fig. $4 A)$ and caused a $57 \%$ decrease in PVR $(0.34 \pm 0.07$

Table 1. Hemodynamic measurements at baseline and after rhVEGF, L-NA, and LY294002 infusion

\begin{tabular}{lcccccc}
\hline & \multicolumn{5}{c}{ rhVEGF rhVEGF rhVEGF } \\
& BL & $(0.5 \mu \mathrm{g})$ & $(1 \mu \mathrm{g})$ & $(2 \mu \mathrm{g})$ & rhVEGF & rhVEGF \\
\hline $\mathrm{PAP}(\mathrm{mm} \mathrm{Hg})$ & $40 \pm 2$ & $42 \pm 2$ & $41 \pm 2$ & $42 \pm 2$ & $44 \pm 2$ & $44 \pm 3$ \\
$\mathrm{AoP}(\mathrm{mm} \mathrm{Hg})$ & $40 \pm 3$ & $42 \pm 2$ & $40 \pm 3$ & $40 \pm 2$ & $43 \pm 2$ & $42 \pm 1$ \\
$\mathrm{PaO}_{2}(\mathrm{~mm} \mathrm{Hg})$ & $21 \pm 2$ & $20 \pm 2$ & $21 \pm 2$ & $21 \pm 2$ & $21 \pm 2$ & $20 \pm 2$ \\
\hline
\end{tabular}

Values are mean $\pm \mathrm{SEM}$.

$\mathrm{PaO}_{2}$, arterial $\mathrm{PO}_{2}$.

$\mathbf{A}$

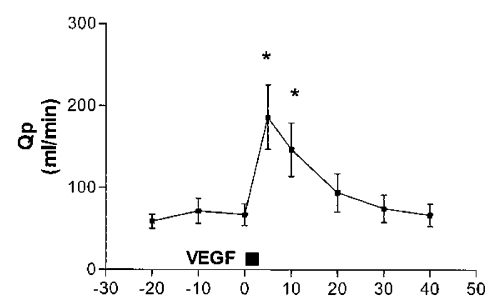

B

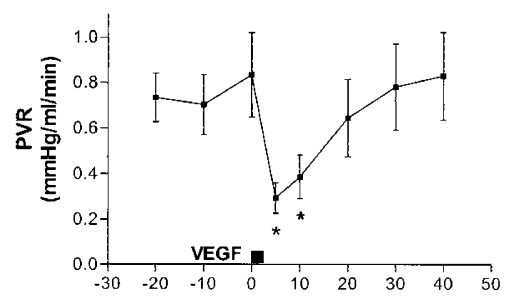

Figure 1. Effect of rhVEGF infusion $(1 \mu \mathrm{g})$ on pulmonary blood flow $(A)$ and PVR $(B) .{ }^{*} p<0.05$ vs BL. 
$\mathbf{A}$

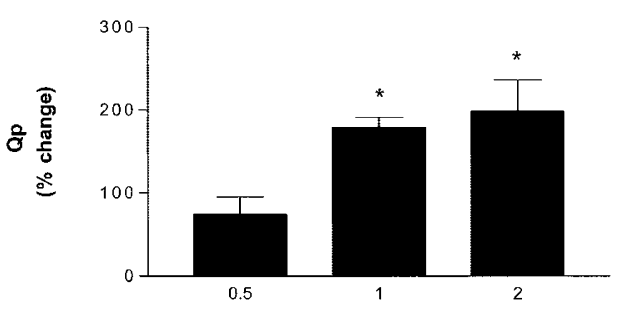

B

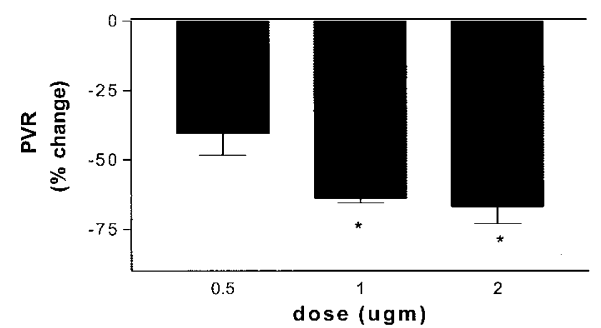

Figure 2. Dose-response effect of rhVEGF infusion on fetal pulmonary blood flow $(A)$ and PVR $(B)$. rhVEGF doses are $0.5,1.0$, and $2.0 \mu \mathrm{g}$, delivered into the LPA. ${ }^{*} p<0.05$ vs $0.5-\mu \mathrm{g}$ dose.

$* \mathrm{p}<0.05$ vs. dose 1

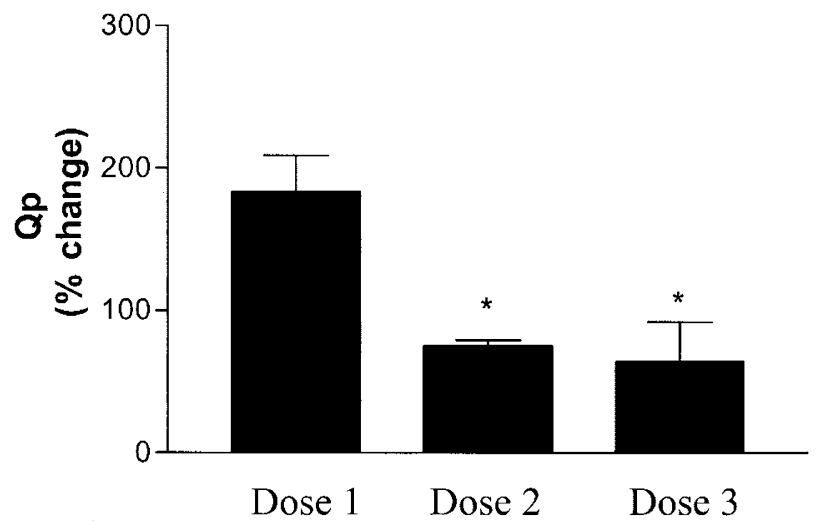

Figure 3. Effect of repeated doses of rhVEGF $(1 \mu \mathrm{g})$ on fetal pulmonary blood flow (Qp). As shown, repeated infusions of VEGF resulted in progressive blunting of the vasodilator response $\left({ }^{*} p<0.05 v s\right.$ dose 1$)$.

$\mathrm{mm} \mathrm{Hg} \cdot \mathrm{mL}^{-1} \cdot \min$ versus $0.80 \pm 0.18 \mathrm{~mm} \mathrm{Hg} \cdot \mathrm{mL}^{-1} \cdot \mathrm{min}$; VEGF versus BL; Fig. 4B). L-NA infusion 10 min before VEGF treatment reversed the vasodilation response to VEGF, resulting in a $7 \%$ fall in pulmonary blood flow $(63 \pm 9 \mathrm{~mL} / \mathrm{min}$ versus $69 \pm 11 \mathrm{~mL} / \mathrm{min} ; p<0.0001$ versus percent change in Qp after VEGF alone) and a $16 \pm 13 \%$ increase in PVR $(0.8$ $\pm 0.16 \mathrm{~mm} \mathrm{Hg} \cdot \mathrm{mL}^{-1} \cdot \min$ versus $0.72 \pm 0.14 \mathrm{~mm}$ $\mathrm{Hg} \cdot \mathrm{mL}^{-1} \cdot \mathrm{min} ; p<0.0005$ versus percent change in PVR after VEGF alone). There was no effect of L-NA or VEGF infusion on MPAP, AoP, HR, or arterial blood gas tensions compared with BL values (Table 1).

\section{Protocol 3: Effects of PI-3-K Inhibition on VEGF-Induced Pulmonary Vasodilation}

Pretreatment with the PI-3-K inhibitor, LY294002, markedly blunted the vasodilator response to rhVEGF, resulting in only a $9 \%$ increase in pulmonary blood flow $(65 \pm 7 \mathrm{~mL} / \mathrm{min}$ versus $60 \pm 6 \mathrm{~mL} / \mathrm{min}$; LY294002 + VEGF versus $\mathrm{BL})$ compared with a $140 \%$ increase in Qp after VEGF alone $(p<$ 0.0005; percent change in Qp following LY294002 + VEGF versus VEGF alone; Fig. 4A). LY294002 + VEGF decreased PVR by $11 \%\left(0.71 \pm 0.19 \mathrm{~mm} \mathrm{Hg} \cdot \mathrm{mL}^{-1} \cdot \min\right.$ versus $0.78 \pm$ $0 . \mathrm{mm} \mathrm{Hg} \cdot \mathrm{mL}^{-1} \cdot \mathrm{min}$ ) compared with a $57 \%$ decrease after VEGF alone $(p<0.005$; Fig. $4 B)$. There was no effect of LY294002 or VEGF infusion on MPAP, AoP, HR, or arterial blood gas tensions compared with BL values (Table 1).

\section{DISCUSSION}

We found that rhVEGF causes NO-mediated pulmonary vasodilation during late fetal life. VEGF acutely increased pulmonary blood flow nearly 3 -fold and reduced PVR by $65 \%$, without affecting systemic blood pressure. rhVEGF exhibited both dose-dependent vasodilation and evidence of tachyphylaxis. In addition, we found that pretreatment with L-NA, an NOS inhibitor, and LY294002, a PI-3-K inhibitor, blocked pulmonary vasodilation to rhVEGF, suggesting that the vasodilator response is mediated by the release of endogenous NO through activation of PI-3-K. Although the critical role of VEGF in vascular development and endothelial function during early fetal life has been well described, this is the first report describing the hemodynamic response to exogenous VEGF in the developing pulmonary circulation.

Past studies have demonstrated that VEGF is essential for normal lung vascular growth during the embryonic period (4, $5)$. VEGF is highly expressed in the early embryonic lung (26), and gene expression increases as gestation progresses (27). However, whether VEGF is vasoactive and can release NO in the fetal lung had not been previously studied. In addition to promoting angiogenesis, VEGF signaling can modulate endothelial cell function and survival (6) and up-regulate eNOS expression in the adult systemic circulation $(8,17)$. In this

A

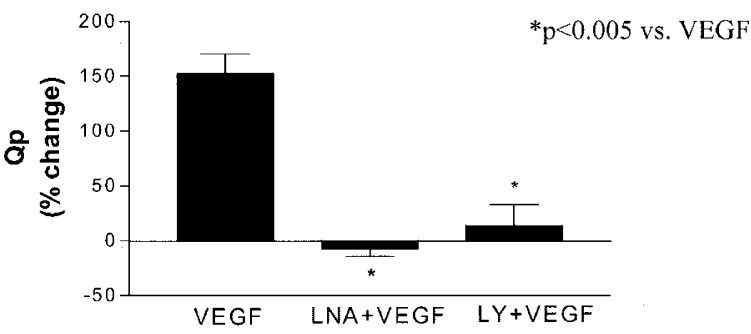

B

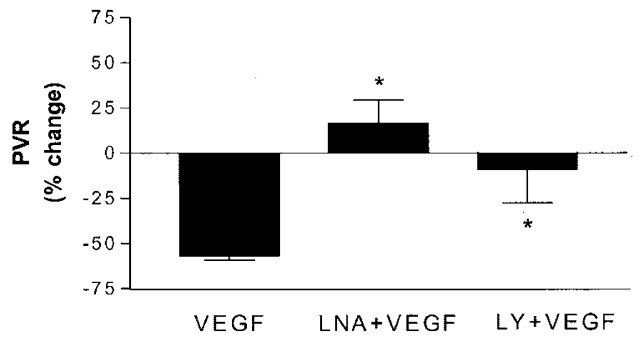

Figure 4. Effect of NOS and PI-3-K inhibition on VEGF-mediated vasodilation in the fetal lung. Percent change in pulmonary blood flow $(\mathrm{Qp} ; A)$ and PVR $(B)$ after rhVEGF infusion $(1 \mu \mathrm{g})$ alone, and after pretreatment with the NOS inhibitor, L-NA, and pretreatment with the PI-3-K inhibitor, LY294002. $* p<0.005$ vs VEGF alone. 
report, we demonstrate that VEGF causes acute release of NO leading to vasodilation in the fetal lung.

VEGF-induced vasodilation has been studied in a variety of settings with a wide range of doses. In vivo studies have consistently demonstrated decreased mean arterial pressure, stroke volume, cardiac output, and total peripheral resistance, as well as tachycardia, after i.v $(11,18,28)$. or intracoronary $(12,29,30)$ VEGF administration. Significant adverse effects have been observed at high doses of VEGF (100 $\mu \mathrm{g}-2 \mathrm{mg})$, including refractory hypotension $(12,18)$ leading to death of $50 \%$ of animals in one study (12). Lopez et al. (12) demonstrated selective local vasodilation with minimal systemic effects after intracoronary infusion of rhVEGF protein at low doses $(1$ or $10 \mu \mathrm{g})$. In addition, chronic treatment with a low dose of VEGF $(2 \mu \mathrm{g})$ has been shown to induce physiologically significant angiogenesis and improve blood flow in a porcine model of myocardial ischemia (30). In this study, we found that low doses of rhVEGF $(0.5-2 \mu \mathrm{g})$ administered selectively into the left lung caused marked pulmonary vasodilation without systemic hypotension. In addition, we found that repeated doses of rhVEGF resulted in tachyphylaxis, which has been previously reported after repeated intracoronary infusion in adult pigs (12). Tachyphylaxis likely reflects diminished NO production, but the mechanisms underlying this response are unknown. Further studies are needed to fully examine the mechanisms responsible for this response.

Persistent pulmonary hypertension of the newborn is a disorder characterized by disrupted vascular growth and function in late fetal and early neonatal life, and animal models of this disease demonstrate alterations in lung VEGF expression (3133). Several recent studies of adult vascular diseases have shown that exogenous VEGF treatment improves angiogenesis and augments endothelium-dependent blood flow (9, 13-16), but the hemodynamic effects of VEGF have not been previously examined in the developing pulmonary circulation. We found that rhVEGF causes marked vasodilation in the developing lung circulation without adverse systemic effects, demonstrating the feasibility of using rhVEGF infusions for disorders of pulmonary vascular growth and function in the fetal lung.

rhVEGF-mediated vasodilation in the developing lung circulation is likely mediated through PI-3-K activation resulting in NO production. In vitro studies have shown that exogenous VEGF increases eNOS mRNA and protein levels in endothelial cells $(8,17)$, leading to enhanced NO production. Animal studies demonstrate that VEGF-induced vasodilation is mediated at least in part by endogenous NO release inasmuch as pretreatment with the NOS inhibitor, L-NA, blocks this response $(11,12,18,28,29)$. Although both VEGF and eNOS protein have been detected in the early fetal lung $(27,33)$, the hemodynamic response to VEGF in the fetal lung has not been previously studied. We report that rhVEGF causes marked vasodilation and that in concordance with previous observations, this response was completely blocked by L-NA. Past studies have demonstrated that VEGF phosphorylation of Akt (protein kinase B) by PI-3-K activation leads to NO release $(19,20)$ and in vivo contributes to acetylcholine-mediated vasodilation (20), but is blocked by the specific inhibitor of
PI-3-K, LY294002 (21). We also found that VEGF-mediated vasodilation in the fetal lung is markedly attenuated by pretreatment with LY294002, suggesting that the mechanism by which rhVEGF stimulates endogenous NO release is through activation of the PI-3-K pathway.

VEGF stimulates pulmonary vasodilation in a temporal pattern similar to that seen after stimulation with several other vasodilator agents. Prolonged exposure of the fetal pulmonary circulation to oxygen, acetylcholine, histamine, or tolazoline causes an abrupt increase in pulmonary blood flow and fall in PVR, peaking at 30-40 min, and returning to BL values by 90 min (34-36). Interestingly, tolazoline mediates pulmonary vasodilation through the release of histamine, a known PI-3-K agonist $(37,38)$. Furthermore, tolazoline exhibits a tachyphylaxis response similar to that described in this study for rhVEGF, and this tachyphylaxis response is thought to be a calcium-dependent process mediated by $\alpha$-adrenergic mechanisms (36). Inasmuch as acute infusions of rhVEGF cause pulmonary vasodilation in a pattern similar to these other vasodilators and demonstrate tachyphylaxis, it is possible that rhVEGF causes vasodilation, in part, through histamine release and subsequent PI-3-K activation, but this requires further investigation.

This study does have several potential limitations. First, although LY294002 has been shown to cause selective inhibition of PI-3-K (21), other growth factors such as plateletderived growth factor, IGF-1, and epidermal growth factor also mediate many of their functions through this signal transduction pathway (22). It is, however, unlikely that the acute effects of VEGF are caused by abrupt release of these other growth factors. Moreover, recent studies have determined that in addition to its effects on endothelial cell function, PI-3-K may also have direct effects on proliferation and migration of human vascular smooth muscle cells (39). It is feasible that LY294002 may block both endothelial cell release of NO and pulmonary artery smooth muscle cell NO-mediated vasodilation. Furthermore, this study examined only the acute effects of exogenous VEGF on the fetal pulmonary circulation, and although the vasodilator effect of VEGF appears short-lived, whether VEGF treatment can alter pulmonary vascular tone or growth in the developing lung remains unknown.

\section{CONCLUSIONS}

We conclude that low-dose rhVEGF causes potent vasodilation in the fetal lung with no adverse systemic effects. This vasodilation is dose-dependent and demonstrates tachyphylaxis with repeated doses. The mechanism by which VEGF causes pulmonary vasodilation is by the release of endogenous NO through activation of PI-3-K because this response is blocked by both the NOS inhibitor, L-NA, and a selective PI-3-K inhibitor, LY294002. We speculate that VEGF may be an important modulator of vascular tone in the developing pulmonary circulation, and that its effects are mediated through NO production. Whether VEGF treatment can enhance endothelial function and sustain NO production in models of persistent pulmonary hypertension of the newborn is unknown. 


\section{REFERENCES}

1. Ferrara N, Henzel WJ 1989 Pituitary follicular cells secrete a novel heparin-binding growth factor specific for vascular endothelial cells. Biochem Biophys Res Commun 161:851-858

2. Leung DW, Cacianes G, Kuang WJ, Goedel DV, Ferrara N 1989 Vascular endothelial growth factor is a secreted angiogenic mitogen. Science 246:1306-1309

3. Senger DR, Galli SJ, Dvorak AM, Perruzzi CA, Harvey VS, Dvorak HF 1983 Tumor cells secrete a vascular permeability factor that promotes accumulation of ascites fluid. Science 219:983-985

4. Carmeliet P, Ferrara V, Breier G, Pollefeyt S, Kieckens, Gertsenstein M, Fahrig M, Vandenhoeck A, Harpal K, Eberhardt C, Declercq C, Pawling J, Moons L, Collen D, Risau W, Nagy A 1996 Abnormal blood vessel development and lethality in embryos lacking a single VEGF allele. Nature 380:435-439

5. Ferrara N, Carver-Moore K, Chen H, Dowd M, Lu L, O'Shea SK, Powell-Braxton L, Hillan KJ, Moore MW 1996 Heterozygous embryonic lethality induced by targeted inactivation of the VEGF gene. Nature 380:439-442

6. Lui W, Ahmad SA, Reinmuth N, Shaheen RM, Sung YD, Fan F, Ellis LM 2000 Endothelial cell survival and apoptosis in the tumor vasculature. Apoptosis 5:323-328

7. Gupta K, Kshirsagar S, Li W, Gui L, Ramakrishnan S, Gupta P, Law PY, Gebbel RP 1999 VEGF prevents apoptosis of human microvascular endothelial cells via opposing effects on MAPK/ERK and SAPK/JNK signaling. Exp Cell Res 247:495-504

8. Kroll J, Waltenberger J 1998 VEGF-A induces expression of eNOS and iNOS in endothelial cells via VEGF receptor-2 (KDR). Biochem Biophys Res Commun 252:743-746

9. Bauters C, Asahara T, Zheng LP, Takeshita S, Bunting S, Ferrara N, Symes JF, Isner JM 1995 Recovery of disturbed endothelium-dependent flow in the collateralperfused rabbit ischemic hindlimb after administration of vascular endothelial growth factor. Circulation 91:2802-2809

10. Ku DD, Zaleski JK, Liu S, Brock TA 1993 Vascular endothelial growth factor induces EDRF-dependent relaxation in coronary arteries. Am J Physiol 265:H585H592

11. Yang R, Thomas GR, Bunting S, Ko A, Ferrara N, Keyt B, Ross J, Jun H 1996 Effects of vascular endothelial growth factor on hemodynamics and cardiac performance. J Cardiovasc Pharmacol 27:838-844

12. Lopez JJ, Laham RJ, Carrozza JP, Tofukuji M, Sellke FW, Bunting S, Simons M 1997 Hemodynamic effects of intracoronary VEGF delivery: evidence of tachyphylaxis and NO dependence of response. Am J Physiol 273:H1317-H1323

13. Bauters C, Asahara T, Zheng LP, Takeshita S, Bunting S, Ferrara N, Symes JF, Isner JM 1995 Site-specific therapeutic angiogenesis after systemic administration of vascular endothelial growth factor. J Vasc Surg 21:314-325

14. Takeshita S, Zheng LP, Brogi E, Kearney M, Pu LQ, Bunting S, Ferrara N, Symes JF, Isner JM 1994 Therapeutic angiogenesis: a single intraarterial bolus of vascular endothelial growth factor augments revascularization in a rabbit ischemic hind limb model. J Clin Invest 93:662-670

15. Banai S, Jaklitsch MT, Shou M, Lazarous DF, Scheinowitz M, Biro S, Epstein SE, Unger EF 1994 Angiogenic-induced enhancement of collateral blood flow to ischemic myocardium by vascular endothelial growth factor in dogs. Circulation 89:2183-2189

16. Losordo DW, Vale PR, Isner JM 1999 Reperfusion therapy: gene therapy for myocardial angiogenesis. Am Heart J 138:S132-S141

17. Hood JD, Meininger CJ, Ziche M, Granger HJ 1998 VEGF upregulates ecNOS message, protein and NO production in human endothelial cells. Am J Physiol 274:H1054-H1058

18. Horowitz JR, Rivard A, Van der Zee R, Hariawala M, Sheriff DD, Esakof DD, Chaudhry GM, Symes JF, Isner JM 1997 Vascular endothelial growth factor/vascular permeability factor produces nitric-oxide dependent hypotension. Arterioscler Thromb Vasc Biol 17:2793-2800
19. Fulton D, Gratton JP, McCabe FJ, Fontana J, Fujio Y, Walsh K, Franke TF, Papapetropoulos A, Sessa WC 1999 Regulation of endothelium-derived nitric oxide production by the protein kinase Akt. Nature 399:597-601

20. Kitayama J, Kitazono T, Ibayashi S, Wakisaka M, Watanabe Y, Kamouchi M, Nagao T, Fujishima M 2000 Role of phosphatidyl 3-kinase in acetylcholine-induced dilation of rat basilar artery. Stroke 31:2487-2493

21. Vlahos CJ, Matter WF, Hui KY, Brown RF 1994 A specific inhibitor of phosphatidylinositol 3-kinase, 2-(4-morpholinyl)-8-phenyl-4H-1-benzopyran-4-one (LY294002). J Biol Chem 269:5241-5248

22. Qi JH, Claesson-Welsh L 2001 VEGF-induced activation of phosphoinositide 3-kinase is dependent on focal adhesion kinase. Exp Cell Res 263:173-182

23. Lewis AB, Heymann MA, Rudolph AM 1976 Gestational changes in pulmonary vascular responses in fetal lambs in utero. Circ Res 39:536-541

24. Cornfield DF, Chatfied BA, McQueston JA, McMurtry IF, Abman SH 1992 Effects of birth-related stimuli on L-arginine-dependent pulmonary vasodilation in ovine fetus. Am J Physiol 262:H1474-H1481

25. Hu L, Zaloudek C, Mills GB, Gray J, Jaffe RB 2000 In vivo and in vitro ovarian carcinoma growth inhibition by a phosphatidylinositol-3-kinase inhibitor (LY294002). Clin Cancer Res 6:880-886

26. Acarregui MJ, Penisten ST, Goss KL, Ramirez K, Snyder JM 1999 Vascular endothelial growth factor gene expression in human fetal lung in vitro. Am J Respir Cell Mol Biol 20:14-23

27. Bhatt AJ, Amin SB, Chess PR, Watkins RH, Maniscalco WM 2000 Expression of vascular endothelial growth factor and Flk-1 in developing and glucocorticoid treated mouse lung. Pediatr Res 47:606-613

28. Yang R, Bunting S, Ko A, Keyt BA, Modi NB, Zioncheck TF, Ferrara N, Jun H 1998 Substantially attenuated hemodynamic responses to Escherichia coli-derived vascular endothelial growth factor given by intravenous infusion compared with bolus injection. J Pharmacol Exp Ther 284:103-110

29. Hariawala MD, Horowitz JF, Esakof D, Sheriff DD, Walter DH, Dety B, Isner JM, Symes JF 1996 VEGF improves myocardial blood flow but produces EDRF-mediated hypotension in porcine hearts. J Surg Res 63:77-82

30. Harada K, Friedman M, Lopez JJ, Wang Sy, Li J, Prasad PV, Pearlman JD, Edelman ER, Sellke FW, Simons M 1996 Vascular endothelial growth factor in chronic myocardial ischemia. Am J Physiol 270:H1791-H1802

31. Partovian C, Adnot S, Eddahibi S, Teiger E. Levame M, Dreyfus P, Raffenstin B, Frelin C 1998 Heart and lung VEGF mRNA expression in rats with monocrotalineor hypoxia-induced pulmonary hypertension. Am J Physiol 275:H1948-H1956

32. Christou H, Yoshida A, Arthur V, Morita T, Kourembanas S 1998 Increased vascular endothelial growth factor production in the lungs of rats with hypoxia-induced pulmonary hypertension. Am J Respir Cell Mol Biol 18:768-776

33. Parker TA, Le Cras TD, Kinsella JP, Abman SH 2000 Developmental changes in endothelial nitric oxide synthase expression and activity in ovine fetal lung. Am J Physiol 278:L202-L208

34. Accurso FJ, Wilkening RB 1988 Temporal response of the fetal pulmonary circulation to pharmacologic vasodilators. Proc Soc Exp Biol Med 187:89-98

35. Accurso FJ, Albert B, Wilkening RB, Petersen RG, Meschia G 1986 Time-dependent response of fetal pulmonary blood flow to an increase in fetal oxygen tension. Respir Physiol 63:43-52

36. Abman SH, Wilkening RB, Ward RM, Accurso FJ 1986 Adaptation of fetal pulmonary blood flow to local infusion of tolazoline. Pediatr Res 20:1131-1135

37. Tucker A, Brown DT, Greenlees KJ 1982 Pulmonary and systemic vascular actions of tolazoline in anesthetized dogs. Pediatr Pharmacol 2:231-243

38. Nakanishi S, Yano H, Matsuda Y 1995 Novel functions of phosphatidylinositol 3-kinase in terminally differentiated cells. Cell Signal 7:545-557

39. Irani C, Goncharova EA, Hunter DS, Walker CL, Panettieri RA, Drymdkaya VP 2002 Phosphatidylinositol-3-kinase but not tuberin is required for PDGF-induced cell migration. Am J Physiol 282:L854-L862 